\title{
Telecollaboration and virtual exchange between practice and research: a conversation
}

\author{
Melinda Dooly¹ and Bryan Smith²
}

\author{
Keywords: research methods; research approach; telecollaboration; CALL; assessment; \\ transdisciplinarity.
}

Interview conducted by Marco Cappellini on the 17th of October, 2019

Marco: There are many different terms to relate to the phenomenon of Computer-Mediated Communication (hereafter $\mathrm{CMC}$ ) and virtual exchange. What is your preferred term and why do you like to use that term rather than others?

Bryan: Let me just give a disclaimer here. I feel way out of my lane with some of these questions. Others I think I'm a little more comfortable with. As an interested outsider to the whole world of telecollaboration and virtual exchange, I think it's best if Melinda starts this. I'm talking about actual research on virtual exchange. There are some components I have some familiarity with, but I've just never done like a true plain virtual exchange.

Melinda: I would dispute that disclaimer, but fair enough. There are so many definitions out there right now. I think probably one of the most referenced is 'telecollaboration' by Belz (2003). It's principally about being in a partnership with internationally dispersed learners in language classes who are using communication tools. All of this is to support social interaction and dialogue and intercultural exchange. That's probably one of the most cited if not the most cited, and then you also have O'Dowd (2005) who has been cited a lot for his definitions on telecollaboration as well. And

1. Universitat Autonòma de Barcelona; melindaann.dooly@uab.cat

2. Arizona State University; bryansmith@asu.edu

How to cite this article: Dooly, M., \& Smith, B. (2020). Telecollaboration and virtual exchange between practice and research: a conversation. Journal of Virtual Exchange, 3(SI), 63-81. https://doi.org/10.21827/jve.3.36085 
Kern and Develotte (2018) talked about online intercultural encounters, which is a term you don't see very often. You see 'Online Intercultural Exchanges (OIEs)' but they called them 'encounters', so with OIEs I'm never sure which one is referred to. And I think that 'virtual exchange' it's a relatively new term. We have all of these terms and probably the most popular right now is 'virtual exchange'. The one I prefer the most is 'telecollaboration', simply because I like the prefix 'tele' which means distance, and I like the word 'collaboration', and I don't know that the other 'exchange' captures the idea of collaboration. I know I have been told that [telecollaboration is] such an old term that nobody uses this anymore, but I still continue to use it for that very reason, because the distance and the collaboration for me are so key. And I think if you want a definition, whatever you want to call it, for me it's talking about geographically distanced partners, it's talking about digitally or technologically supported communication, and it's talking about collaboration. In the realm of education, it would be the mutually supported learning. I don't think you can get mutually supported learning just... it does not happen, it's not spontaneous, it has to be set up very carefully. And so I don't know if 'exchange' catches that. I'm fine with it and sometimes I'll use it, but, for me, 'exchange' doesn't always capture that inherent quality of mutually supported learning and sharing, and that's why I still prefer 'telecollaboration'.

I give my students an image I made many years ago and I call it the collaborator-metre. I show a big thermometer with the different kinds of exchanges and how much collaboration is going on. The lower is what I call the 'show and tell'. One partner does something, some learning experience and shows it or explains it to the other partner and that partner does something similar and you have that show and tell aspect. It is kind of low I think in collaboration. And then you have the 'zigzag', where I do part of something and hand it off to you, and then you do something, add to it, and hand it back. And what I put on the top is the 'cogwheel' which is the idea that each part works together in order for the gear to move, all have to work together in a mutual fashion. And of course that's the hardest to get to, but for me that's the ultimate telecollaboration.

Bryan: I like that image of the approach. I think that's helpful for me to think about different levels of sophistication.

Melinda: Obviously it depends on the level of the learner. At some levels it might be best to start by trying to implement a 'show and tell', and maybe throwing in a few sort of activities of 'zigzag'. I've worked with very young learners and most of it has been on the level of 'show and tell' and a little bit of 'zigzag', but we've never been up to the level of a total 'cogwheel' type of collaboration. But with adults, with the higher level of the language that you are using, or the languages if you want, you could maybe push for that sort of 'cogwheel' type of collaborative learning I think. 
I would say for the definition you would definitely need the geographical distance element; it doesn't make sense to have somebody to talk on the computer if they just can stand up and walk around and go to the next room and ask them something, right? I'm saying that because I've actually seen some case studies of people doing that kind of exchange where they are just in two different rooms in the same building and I thought: why?

Bryan: For that last point, I take your point on that. It just reminds me of the old days of Synchronous CMC (SCMC), where some of the SCMC stuff with text-based chat was exactly what you are describing. In those days it was a proof of concept type of thing. The question was: what is the nature of this communicative activity? The learners would be sitting next to each other with pen and paper and look at the pictures or whatever jigsaw task they are doing. But in the late 90's, we were still asking "what is the nature of this interaction?", is there any negotiation that happens? For example, when there's a communicative misstep or a meaning nonunderstanding or misunderstanding. Then I agree with you, to still be doing that kind of thing... I hope people aren't doing the computer lab stuff anymore.

Melinda: I don't think it's very common anymore, no. It may be in countries where telecollaboration or virtual exchange or whatever you call it is not as common.

Bryan: Yes. For what I've done most recently, I haven't done this using your definition of telecollaboration. I agree that traditionally the distance part is truly necessary for all types of telecollaboration. But what I've started doing, just because I've noticed that we don't make use of the rich linguistic resources that we have at this giant university ${ }^{3}$, I've done what I'm calling a telecollaborative study with my Chinese international students paired up - they never meet each other - with Chinese intermediate-low students taking a sort of gateway to China culture course. Basically we try to align the tasks in a way where they are meaningful for one another. But it's not telecollaboration (based on Melinda's definition), they are all ASU students.

It's that kind of, you are still doing the same kind of things in terms of cultural learning, and hopefully getting some of the linguistic benefits of that interaction. And they are at a distance, some of them are ASU online students which could be in China or the UK, anywhere really, interacting online with the Chinese counterparts that are ASU students. In terms of going a step forward, you know just looking at the sales of desktop and laptop computers as compared to smartphones, to my mind it almost makes no sense to use desktops and laptops anymore for this kind of work (laughs). And that's what we are trying to do, that kind of proof of concept we talked about before: how can we

3. Arizona State University, hereafter ASU. 
do this weird kind of telecollaborative exchange purely with mobile apps? One thing we did, we decided to use WeChat as the app to use for the synchronous and asynchronous exchange. Because it was part of the cultural learning for the American students studying Chinese. Of course, all of the Chinese students know what WeChat is and it's kind of embedded in their own culture as far as my Chinese students tell me - they use it for everything. And the American students usually use WhatsApp, maybe, but they are used to use other kinds of things. We kind of side stepped some of those real challenges that you have for telecollaboration as far as I hear from people. As I said, I've never set up a distance exchange before, but I've had people Zoom in and talk about it in my classes like Mirjam (Hauck) and others. It just seems like such a colossal task to set up, to find a good partner, set up a functioning exchange, and then maintain it and sustain it over time, and I'm just way too lazy for that.

(laughs)

Melinda: Once you can get the right partner, it can be sustained, ok. But yes I completely agree with you: that it's just a lot of work. You brought out something that also keeps coming out when you try to define what is telecollaboration, I think is the vast array of what I call configurations. Is it formal learning, informal learning, is it a one-time task, is it just a few tasks of getting together and discussing ideas or is it completely integrated into everything you do in your curriculum? And I believe it was Goodfellow and Lamy in 2009 who brought that out. It's almost impossible to try to put a definition on what constitutes telecollaboration. Which is one of the reasons that I did the collaborator-meter, to show my students. My classes focused on learning how to do telecollaborative projects in primary and secondary education. And I think that we tend to think that telecollaboration only happens in language classes, but I'm beginning to see more and more examples in other disciplines. So it's not as if we [language teachers] have the claim on telecollaboration or telecollaborative learning. And I think that the fact that technologies are evolving, and more people are getting involved, the way we see learning nowadays is in a different way. All that is emerging is going to push what is telecollaboration further and further really.

Marco: Bryan, in a chapter with Doris Torres, you also used the term computer-mediated intercultural exchange (Torres \& Smith, 2018). I wondered if that came out of a reference I missed, or if it is a particular way of looking at this kind of practice and of research?

Bryan: That's what Doris Torres used and I subscribe $100 \%$. We were asked to do a chapter on intercultural exchanges. So I think this just kind of emerged out of the review article on this stuff, and the nature of that volume. I'm not bound to that term, but I think that perhaps the stuff that I was describing is better described as computer-mediated intercultural exchange, frankly because 
you don't have the 'tele' part in it, the distance part. I'm not one that tends to get hung up on these distinctions as long as we understand what we are talking about, we understand the limitations of every acronym. I just had Bob Blake Zoom into my class yesterday (thanks Bob) and we almost didn't pass Question 1, like us today. We were talking about what is CALL ${ }^{4}$, is CALL the right term, is it TELL rather than CALL? If CMC, then is that term helpful at all? You have to delimit what the component parts are, right?

Marco: The question I had in my mind when I saw this chapter was, having talked with you about the predominance, or what you observe as the predominance of mobile technologies and MALL', I wondered where this 'computer-mediated' or 'technology', or just 'online' came from, but I understand now. So, what is your current research on telecollaboration for Melinda, maybe on $\mathrm{CMC}$, or online communication for you Bryan?

Melinda: Recently I've done two different studies and getting into some applications. One of them is on a macro level, a longitudinal study. As you said Bryan it's really difficult to find and sustain a partnership, and I've had a sustained partnership with UIUC ${ }^{7}$ for 15 years. Randall Sadler and I, we joke we are kind of the grandparents, we've been together a lot. We've just worked together, with a PhD student of mine, to contact former students from 15 years ago up to last year and found out who's actually a practitioner. We've contacted over 500 people and then we came up with people who are now teaching, and now through interviews and questionnaires, we are looking into the impact of having experienced telecollaboration in pre-service training. If there are any detectable patterns of impact from our class in what they are doing as telecollaborators now as teachers. So that's one area, that's the first time I've tried to do something macro and longitudinal, because I'm mostly in micro-level. I mostly look at interaction from a very emic perspective: what type of exchange, what's happening in the exchange, applying conversation analysis or interactional analysis. I've been working recently with Enza Tudini ${ }^{8}$, we are looking at the effect of small talk, topical small talk, and troubles talk. I know that that can be annoyingly, maddingly small, but after a while, the collections begin to show emergent patterns, that you can then bring to other areas and say: look, these emergent patterns are ways that teachers can support this interaction more fruitfully etc. So mostly do micro-analysis emic studies. And, like I said, I'm doing this longitudinal, over the course of 15 years, what is the impact of telecollaboration on teachers' own teaching now.

\footnotetext{
4. Computer-Assisted Language Learning.

5. Technology-Enhanced Language Learning.

6. Mobile-Assisted Language Learning.

7. University of Illinois Urbana-Champaign.

8. University of New South Wales
} 
Marco: I'm very curious about these second or third generation telecollaborations. Maybe you can find across the students that were in your own telecollaboration at the beginning, if there are some parts of the telecollaboration that have been transferred, maybe abstracted from the telecollaborative setting and then implemented into an in-class setting.

Melinda: We are seeing that impact and we are seeing even more from the recent years, because at the beginning it was sort of an add on. When we first started, neither of us knew what the heck we were doing, right, and little by little in the last five years it has become an integrated cogwheels part of my course, and they [our students] have to really work together. Everything they do is integrated in working telecollaboratively, we even have the same course programme now. Even though we have different classes: I've got undergrads, he's got grad students. He's in a whole different university etc. But we plan our programme 100\% together. And they are working in lockstep and that's how integrated telecollaboration is now. And we started doing that 5 years ago, and the impact that we have been seeing shows that. We've even been seeing students doing telecollaboration in their internship before they have finished their teacher education degree. That's something we didn't see before. So I do think it's having an impact. Of course, they're hearing more about it because it has become more popular too, and that's another aspect of it, I think. I think it's definitely growing; it's there and everybody is seeing it now. And I'm surprised when people don't know what it is, you know. I'm almost "what? You never heard of it before?”.

Marco: It probably depends on the places, because when I talk about telecollaboration here ${ }^{9}$, it's not that wide-known. We are getting more into teletandem, but it's a very specific kind of telecollaboration, so other possibilities are not very known, at least here in my university. I think I'll have a couple of questions for you Melinda, but before I'd like maybe to hear Bryan on the research you are currently doing on CMC and also on mobile communication.

Bryan: Listening to how you and Randy are working together and planning from the ground up, I mean that's, as an interested non-expert - a kind of outsider to the field (of telecollaboration), that seems to me like the best way to do it. But also those examples are probably difficult for most people.

Melinda: So integrated I would say it's not very common. Because it is a lot of work. We've been doing this for 15 years and every year we change it in some way, and we spend at least a month revising and redoing. And considering that we are veterans of it, I doubt that somebody as new can do it so integrated, to be honest. I'm not trying to make it look like this is some sort of big thing here, but I do think it's a colossal effort, but that it pays double. Because once the plan is there, it rolls. It's

9. At Aix Marseille University. 
just the planning, it's all in the planning and staying together, you know, stay on top of everything and making sure that for example when my students go on strike next week ${ }^{10}$, which they inevitably will, you know, you got a plan B etc. But the planning is there, and something like this probably doesn’t happen that much. But teachers have to plan for these kinds of things anyway.

Bryan: Yes, that's the biggest part of any new course or even a refurbished one that I dig out after a couple of years. It has to be planned really well. At least for me. I know some people can come in with some kind of general guidelines and run a seminar style course, but that's not me. I need to be very structured and our students I think appreciate it, because I have students from all over the world, maybe like you do, and they can all relate to that. Yes, so just to answer your question...

Melinda: Can I just do one ad here?

Bryan: Sure.

Melinda: The EVALUATE project that we just ended, created a model for people interested in getting started (The EVALUATE Group, 2019). And it's designed for people who have never done telecollaboration and want to get started. And I think that might be a good place to start and then little by little you get eventually to start integrating more and more aspects.

Bryan: I saw that was one of the outcomes that was really great, like how to do it. I know the students need something to latch on to, even if it's flexible enough to link it to their own context. So, basically the way I got started in researching telecollaboration/virtual exchange was just kind of one of those creations out of necessity situations. I have foreign language students, TESOL ${ }^{11}$ students, applied linguistics students, in my CALL course. One thing that they are always lamenting is the amount of time that they have, the amount of native-like (let's say for lack of a better term) input or interaction with highly proficient speakers of that language, because I've got 38 students in there. And if you look at it, and if you just kind of look at the number of hours that they spend in a classroom under a best case scenario at an American university, and then juxtapose that to what the FSI ${ }^{12}$ language estimates are in terms of how many hours you need to get to even a basic proficiency level, or a working proficiency level, we don't come anywhere close to the number of hours. And so, we looked around, a graduate student colleague of mine and I looked around and said: well we have all of these Chinese students studying at ASU, as well as other countries, but

\footnotetext{
10. To protest against the trial of members of the Catalan government.

11. Teaching English to Speakers of Other Languages

12. Foreign Service Institute
} 
predominantly Chinese, for now anyway. And you know our American students learning Chinese have one teacher, and that teacher has a very grammar-oriented book that she or he has to work with. And for the online students it's a little bit worse, because they only get these one-on-one conversations periodically with the teacher via Zoom. And so this was the genesis of this, let's call it intra-institutional telecollaboration study. The students never met each other, but the motivation was trying to harness the power of mobile technology for this kind of intra-institutional exchange. We thought it would add value to the experience, to the campus experience for students from China. In my class they have to do a project that is a survival guide for students that come from China the next year. And so the best way to do that is to talk with Chinese students about the struggles they have and how they overcome them. Inevitably the number one and two issues that the Chinese students have is the food and how to get what you need to 'survive' in Arizona as a Chinese student. And then making friends. Those are the first two. Because apparently, I know virtually nothing about China, but that is the number one problem that they say they have, they kind of stay in these pockets of Chinese students because there is such huge support, right? It's kind of natural I suppose. And so we've just tried this proof of concept: let's just see what happens. We thought it dovetailed nicely with the main challenges in second language teaching in general, like authentic communicative opportunities as well as some of the challenges that the literature suggests are typical of the telecollaboration studies. Each of the students - both sides are language and cultural experts and so that was our starting point. And when I looked around, I found very few mobile-based telecollaborative studies and just a small handful of Chinese-English and then maybe two that used WeChat, which struck me as kind of odd.

We also thought that this kind of exchange might facilitate broad interest among the American students and so you don't have one of the main issues in setting up a telecollaboration study, that is, like Melinda said, the time to set it up and run it to work efficiently. You do need to build it into the curriculum, which is what we did with the culminating task. The problem for us was that the Chinese students' proficiency in English was much higher than the Americans' proficiency in Mandarin. This is one of the typical problems you have unless you set up the exchange like Melinda and Randy do, where you have these disjointed tasks in which we get different proficiency levels, at least in English. Inevitably the non-native English speaker's English is better than our learners here in the US. We are trying to fit those tasks into the curriculum. We didn't overcome that challenge $100 \%$, but we did set differentiated goals based on the proficiency levels and on the nature of the two courses. I think this helped us alleviate the lack of participation you sometimes find in some of the exchanges where things are heavily weighted towards the alpha in the group, because we built that into the syllabus. It was almost like if you didn't communicate with your interlocutor and didn't cover these points (it was essentially a two-way information exchange task) you really couldn't complete the task sufficiently. The time zone difference, which is a systemic issue for telecollaboration, is not really an 
issue anymore with the intra-institutional approach. We still have challenges with the assessments, but I think that's something you've always got. Just looking at what they did from a TBLT ${ }^{13}$ approach, they completed the task successfully, they were able to exchange the information and we really didn't give them lots of prompts in terms of the specifics to discuss other than, for example, talking about making friends. We had a series of enabling tasks on how best to approach people and what are those situations where you might be able to meet someone with a shared interest and not be offputting about it. Then we thought: let's just concentrate on the linguistic side. One benefit we were hoping to find was some hint of linguistic gains and some attention to the linguistic elements rather than just the cultural side, which was the main focus. So we coded all of the transcripts for language related episodes, to use a very blunt instrument, and see if there was any kind of focus on language itself. We had some interesting findings.

Marco: I think there are lots of interesting things in what you are saying. I'd like to dive in from a research prospective: what you both mentioned about the time that is needed to set up a telecollaboration or exchange is very interesting. It always struck me when I was a student learning to become someone who wanted to collaborate in this field. I also think there are not that many studies about this part of telecollaboration; at the beginning we had lots of studies on people starting to telecollaborate and looking at what happens with the learners, while now we start to see studies and books, such as the one you, Melinda, co-edited with Rob, about the teachers' perspective on that. I wanted to know how would you take into consideration the implementation from a pedagogicalengineering side for research of this method and what would be the tools to look into that? I'm not sure if my question is understandable...

Melinda: I'm not sure I understand you, sorry.

Marco: A teacher who wants to collaborate has lots of things to do and there are many different ways to approach that work. I am not aware of many studies on this part of telecollaboration, except for the one I mentioned earlier. So, how would you have a research or study about this side of telecollaboration which is usually hidden in the majority of publications we have on the subject?

Melinda: I am not sure I agree with you on that because in most studies that are looking at teacher education and telecollaboration one of the first things that ever comes out is the teacher saying that it is time-consuming. It was evident during the EVALUATE project, we all agreed on that. I'm not sure if I understood your question: are you asking how to research into the time?

13. Task-based Language Teaching 
Marco: Not specifically the time that is needed but rather what is done during that time that is needed to telecollaborate.

Bryan: Maybe using the EVALUATE or the handbook or guide, something like a kind of step by step or something like that?

Melinda: I think you could do some research into the amount of time that it takes for teachers who've had no training in it and decide to do it on their own versus a teacher that gets the training (through whatever: EVALUATE, a course like mine or similar). There are pockets of teacher education that are doing explicit classes on how to set up technology-enhanced project-based language learning, so maybe you could compare those two classes for research: you have teachers coming out who've had no training, you have teachers coming out who've had it, who takes longer and I think that that would be a proof of concept. I would dare say that those who've had the training won't find it as time-consuming because they know how to do the planning effectively. Maybe. That could be an interesting research if that's what you're asking.

Bryan: As you're talking, I'm thinking that, yes, that would be one step (training versus no training) and of course we would expect the ones who got trained to do better. What would really be interesting to me (I won't do this kind of research, but I would love to see someone do it) is to take the EVALUATE guidelines and it should be an iterative process because you are not saying "this is the answer" but rather "based on our research and our collective wisdom, here's our best guess" of how to do it, and then test it out empirically and see what happens when you try those two variations. To me that would be interesting and helpful in sculpting... maybe there's a forking path of some of the steps, it's usually this way or this other. It's not just a one size fits all. We know there is a limited number of possibilities.

Melinda: That is something you said much earlier Bryan. You are asking about what's research and you brought up the question of time, but I think there's another aspect of telecollaboration or virtual exchange or OIE or whatever you want to call it. For me, this is where there needs to be more research: assessment, you said it yourself, there is very little work being done on assessment. I feel very fortunate right now that we just procured a Marie Curie scholarship and we have a fellow here who's doing assessment in virtual exchange and she's going through right now doing a literature review, she's like: “There's nothing here, there's nothing here, there's nothing here” and I'm like: "I know". So I think there is an area. Teachers don't like to assess; that is the bane of every teacher's existence: assessment and evaluation. And it's even more complicated now that we have this whole idea of lifelong learning, of competence-based learning, of continuous assessment, and it gets more 
and more complicated: how do you assess if there have been language gains because they've been talking in Chinese online? That's really hard.

Bryan: They could use a couple of blunt instruments but then they may be not sensitive enough to discriminate, so you'd almost have to look at things that we think are indicators of gains or going down the path of acquisition, like, just to use an example: Language Related Episodes (LREs). When I come at it from a cognitive interactionist perspective, so some people would not agree, but if we have those instances of LREs, then there is something going on where they are focusing on language and then we can... maybe we don't have the individually sculpted post-test right for that learner, because that's what you would need right? Because the blunt test instrument that everybody is using at the end of the semester is certainly not going to pick up on more than a couple of the things they talked about. To sculpt some kind of post-test based on individual exchanges, I've done it and it's a nightmare. It would also have to be an indirect connecting of the dots. I told my students: "You don't have to show (with CALL research) that it's better, you just have to show that it is not any worse, and that you didn't have to spend thousands of dollars and that it didn't take you tons more time". The gain to show it being better can be student satisfaction and self-report data, which I'm always a little sceptical about but certainly it has value: when you ask the students at the end of the class, "what is your satisfaction?”, they may grade it like a C, but then you ask them that after something innovative like what you and Randy do and they are likely to say that it was really cool and that could be a bit due to the novelty effect. Anyway, they tend to say that they were able to communicate more because of the hand-holding that you do with the students throughout, that they were kind of overcoming the unwillingness to interact in the target language. Now, I'd also say that, from my data, we saw one group out of the five was just awesome, they did everything we hoped they would do where most of the groups did not, so most of the data comes from one group but that's helpful for me because it basically tells me it was kind of a mismatch for some of them, or that we did something wrong. Some of them just picked up and went for it, maybe it was personality type, maybe it was proficiency level, we don't know that, but in order to really get the most out of these exchanges you have to have students that are on board with it, because a lot of times they are expecting a certain... like for some this might not be what they consider language teaching and learning at all because they come from a different educational culture.

Melinda: I think that there is some research being done on expectation management on telecollaboration, so I think that that's a very fruitful area. What you were saying made me think about something related to another question: the different frameworks and whether they can be integrated or not. I'm no expert on quantitative analysis, but I do know that sometimes when I do interaction analysis and I'm pulling out, from a two minute transcript, the ways someone uses a word and then picks it back up and uses it again or somebody else uses it or whatever in a different 
moment in the discourse or a later exchange. It's a bit like what you were saying about LREs. I've got these episodes where they are negotiating and there's recurrence in the use of a word, but I always get a question from the audience or reader: "how do you know if they used it again later?", and you don't. I'm thinking that maybe there is the possibility of doing, as you said, a blunt instrument of testing and then maybe go back and say: they were able to come up with the word they needed here, let's see if we can find in the interaction analysis where that use came into play first; did it come into play during the telecollaboration or not, because if it didn't then it would be more difficult to say that was due to the telecollaboration that they were able to use whatever language target you have in the main final output. Again, I'm no expert on assessment nor am I an expert on quantitative analysis, but I can see that merger, perhaps, of what is often seen as sort of a big gap in emic perspectives.

Marco: For that side of the study of interaction where you want us to understand if something that is present at some point is used afterword, I think that Bryan, you have some things to say related to the work of what you did with Marije Michel on alignment, probably (Michel \& Smith, 2018).

Bryan: I would say I'm no longer worried about those kinds of comments. I'm thinking more and more about why should we expect... I mean, you can look at the transcripts later and if you're talking about lexical alignment and uptake or whatever you want to call it, methodologically is a very big problem to show that because it's just like trying to show the effectiveness of corrective feedback on a particular word: a student may say yes, but that might not need to appear later in the transcript. So you shouldn't necessarily expect, at least in CMC, for there to be clear evidence of positive uptake based on this negotiation that they were doing, because they can just scroll back to see the word. That's where eye-tracking comes in that is potentially helpful. The way I would look at it is: well, we don't know if the learner didn't passively know that structure or passively know that word and just couldn't produce it at that time and you've got the input that shows a new lexical item or phrase and then you see the uptake or the alignment later and then you don't know if that's learning, you don't know if they learned it later. I would say that's where teaching comes in and what I would suggest to teachers is to not just use that task and then move on, but rather use that task again and the transcripts in the next class where you actually work with the students and the chat transcripts to kind of reinforce their understanding of this new structure or lexical item. Of course, it takes a long time to learn aspects of language and a kind of ‘drive-by’ approach isn’t going to do it.

Marco: Coming back to the issue of assessment, I had a very good philosophy teacher, who explained to me that when you start looking at something, the tools you use to look at that thing will have an influence on how you see things. So, my question would be: how do you think that the research methodologies or tools that you use have an influence on what you see in telecollaborative exchanges or online interaction? And how do you think that these would enhance or inform the ways of 
assessment or how assessment can be done for these kinds of exchanges? For instance, you were talking about the micro-level conversation analysis, you probably see things in interactions that are different from what you could see with the framework of alignment, or the input-interaction-output framework. How would you see that kind of influence in forming the assessment that you can build on language learning or telecollaboration learning in general?

Melinda: That's a tough question. I think that whatever research framework you have will always make an impact on the other aspects of your life. I'm a conversation analyst so that has an impact on how I set up my classes, on how I assess, on everything I do. I mean, I almost automatically analyse a conversation when I'm having it. I'm not sure I can really answer that question because I'm not sure I can step away from that framework... I mean, I've tried out other frameworks, of course. I don't know that when I'm teaching that my research frameworks are coming into play or not, to be honest I never thought about it. I'd like to know what Bryan has to say because I'm struggling with this question.

Marco: Do you change the way you assess students or pupils because of new ways of seeing things after adopting a research framework?

Melinda: I think what had a bigger impact on changing the way I assess is based on research I've done into assessment, which is not much. There have been moments in my teaching career where I've been unhappy with the way I'm assessing or haven't felt satisfied with the process that I was applying and felt like it wasn't effective enough. So, I've done research in that sense to improve my own teaching but that was more practitioner research. It's almost impossible to take the microanalytical approach into your teaching because you don't have time, to be honest. I've used transcripts and asked students to look more closely at their own interactions for, as Bryan pointed out, for them to analyse "I could have said it this way, I said it that way, this could have been done differently" but I don't know if that's really the fusion between research and practice that you're talking about. I've never thought about it to be honest. I mean, it is a really tough question!

Bryan: I don't think I have an answer that's anywhere near as coherent as Melinda's on this, so I'm going to go in a different direction and say one thing about what we discovered based on the tool that we were using for this CMC intra-institutional telecollaborative study with WeChat. We allowed the students to make use of whatever affordances that WeChat has. We asked them to go ahead and use video, image, and text and audio and you know try to really make use of this, and the Chinese students already knew how and the American students were trained. But one thing that we didn't anticipate - and this has to do with assessing not the student outcome but how we should cope with what was going on - the use of pinyin in Chinese. We had categories of LREs: lexical 
form, discourse, affective, pronunciation, that's just what we grabbed from the literature. And we had a real challenge with pinyin. You know pinyin can be used to generate typical pronunciation like these minimal pairs that we find in the data and that our student is mispronouncing. Or even a Chinese student who has a regional pronunciation, a Cantonese pronunciation rather than some other region, and this did come up where the Chinese were correcting each other. And so, one is to provide the pronunciation guide for the characters from the native speakers to the learners and the other way to code is that pinyin is providing lexical information without characters. And so this was a struggle for us: how do we code it because in the latter the focus is on lexis instead of pronunciation, and so this is a methodological challenge that we had, based on the technology that we were using and it wasn't really clear, like usually a pronunciation LRE is a pronunciation LRE, but in this text-based environment it was no longer clear, right?

Marco: And especially for that language. Yes of course and personally I really like this thing that in research you come up with a way of, let's say a grid if you want with some categories that you want to use on your data, and then the data tell you 'no, you have something different here'. So you look at the data and build up new categories and that's...

Bryan: I really like those encounters too, but it's really like 'oh man' I thought it was already hard enough. Now we've opened up this can of worms.

(laughs)

Melinda: I think that's an excellent point that you asked me: what I tell my PhD students or other researchers: embrace the disruption. I think that inevitably research is going to bring up new points and new challenges and gaps in previous research. Another area that I also think there is not enough perspective on - and please correct me if I'm wrong, I'm not trying to sound accusatory - but I still feel like it's kind of a monolingual hegemony of perspectives about how these exchanges work, despite the fact that we are in such a plurilingual world and so the plurilingual education, plurilingualism that has become mainstream. I'm still missing it a little bit in the perspective of the research that we apply to these exchanges and the multimodality which younger people are so used to; switching back and forth in so many different semiotic affordances. I think that we tend to look at semiotic affordances in a reductive way, but there's so much semiotic, merge of semiotic communication, and plurilingualism. I hate to use this, I don't want to use this word because it's very trendy, but the translanguaging; trans-everything now, the transcaring, translanguaging, and transculturing, and I don't know what else 'trans' there is now. But telecollaboration and virtual exchanges should be in the middle of that. There's a boiling pot of 'trans', and maybe we need to bring it in more into our work. This [telecollaboration] exposes it, the fact that you are working with someone in languages 
you don’t usually work in. You're coming up with these new challenges, disruptions, and it should push us to bring this into our research.

Marco: What do you think about the term 'transdisciplinarity'? Have you ever had to work within a team, a research team with people from different disciplinary perspectives and having this kind of disruption that we were talking about, when something does not fit with your categories, but coming in not from the data, but from a colleague from a different discipline?

Melinda: It never got off the ground, but I was working on a big research grant, transdisciplinary, and we met, we were computer scientists, and neurolinguists, and myself.

Bryan: It sounds like a joke. Is there a punchline to it? They walk into a bar... (laughs)

Melinda: Actually we did meet in a bar! It took us ... I don't know we'd been talking for about four hours before I finally said: “oh, when you say 'tasks' you mean so and so”. And this is after two or three bottles of wine! (laughs). So, yes, transdisciplinarity it’s a whole different... It’s very complex, because you don't speak the same language, you really don't.

Bryan: I don't know much about this because we tend to work in silos here. It sounds to me that in that encounter, the transdisciplinary would emerge out of that conversation, that up until that point it was just interdisciplinary. It's just the way I kind of interpret it when I hear 'interdisciplinarity', everyone coming at it from their own perspective, but it's not transcending those perspectives, it's not an alchemy. Here's how we're looking at this, not just from different perspectives, but this is the new perspective, where you do bring component parts and constructs and definitions from other places, but you know, maybe they flatten out to a real hybrid that wasn't there before that meeting.

Melinda: As I said, it never really got off the ground for various reasons, so I don't know if we ever gained that transcendence. But it was an interesting adventure I have to say.

Bryan: And one of the problems I think is a very practical issue, like a lot of times things are complex but in some ways they are very simple. From a US North-American perspective in academia, one of the reasons is the way we reward scholarship, what we consider scholarship, and how we 'count' things. It almost discourages this kind of collaboration and this kind of what Jozef Colpaert (2012) would call a 'slow research'. Which is really what you have to do. He's right about that, and we see too often people just coming in in a very reactionary fashion. But you know you have to, it pushes us to produce two articles, two articles a year at least. A proper think piece it's just not that kind of research. You can't ask a junior faculty to engage in this kind of research, they should play the long 
game. But there are certain benchmarks they have to meet, that are short term benchmarks. And so what that does create is a situation where you are a fool, right? Professionally. If you put all your eggs in that basket of writing a book, let's say, which is also fine, but that is a huge undertaking. You are much safer doing this incremental, quick research, right? Which is kind of the opposite of the stuff we were just talking about. So there are these things, these tensions, pulling this best intentions research agenda, pulling at it. The people that actually can do it are people with more comfortable, safer settings, academically. But those aren't always the people who, present company excepted, those aren't always the people who are as in touch with what's going on currently in their respective fields.

Melinda: Very valid point, I completely agree with you. The pressure now is on output and it doesn't always lead towards what... You asked the question Marco: what is learning? That is the Holy Grail, that's what that is. What is learning? The only way you can do research in what is learning, is to dedicate a long time to it, and you know, nowadays with, as you said, this pressure, you can't take time to try to tease that out, to shadow students for five years or whatever you want to do. Or to do interdisciplinary work, because the ground work, trying to come to common understanding, terms, takes time. So yes, I completely agree with you Bryan. It's a very difficult time right now to be a young researcher.

Marco: Since we are talking about what will be the future for future researchers, what do you predict in terms of research methodologies, of tools, of approach? What do you think will be needed by the future PhD students to come or maybe that you are supervising?

Melinda: I think that there is a need to take a more plural, plurilingual perspective, (without using the word 'trans' again), plurilingual, plurimodal, pluralist perspective to everything and not think that a language, a virtual exchange, or telecollaboration is one language sort of thing, that it's inevitably hybrid, it uses a lot of different languages and I think that needs to be accepted as well, and probably there needs to be more research in that area, for me.

Marco: Is that a semiotic perspective?

Melinda: Not just semiotic, plurilingual as well. I mean the translanguaging - I'm not going to go into the big debate about translanguaging - I really like what García and Otheguy (2020) say, they are quite radical about the idea that languages, boundaries of languages are social concepts, they are not real. And here you have an example of the Chinese correcting each other, which kind of exemplifies that idea of what is correct language, what is language, in language use. As teachers we tend to think that there is one ideal. And that's going to go into research in assessment, going 
into the configurations of virtual exchange, it's going to go into all of that. That's the kind of change perspective on all of that, to some degree.

Bryan: My answer is kind of more micro-level than that I suppose. Because I was thinking just about my specific CALL graduate certificate students, if they continue on down this road of technologyenhanced language learning or CALL or whatever you want to call it. Right now there is still such a wide mismatch between what we do as CALL researchers and all this cool stuff I think that we are showing in terms of the efficacy of harnessing technology for instructed second language learning, as well as language learning in the wild as Steve Thorne would say. There's still such a huge mismatch - and there always is - between what the research says we could/should be doing and what people are really doing in language classrooms. And my students confirm semester after semester that, ok I'm going to try to use much of what we are talking about, fit it in somehow. And I'm really sceptical about it. It seems that the larger the university, the more rigid they are in implementing research-based approaches to instructed second language development. In the US of course, it's largely because the literature faculties are in control of everything and they are not that interested in applied linguistics and in instructed SLA ${ }^{14}$ as far as I can tell.

One way to answer that question, one thing that pops into my mind is that I want our future researchers to be able to look at learning - you asked us what was learning so - just look at, to continue to be able to understand things in a new way that persists over time. Because very often we tend to look at things in our myopic point of view, we have two windows open to the world and that's really all that we can handle. This just goes back to work that Phil Hubbard (2006) did, his evaluation framework, and Bob Blake's work. I encourage them to forget about the specific technology they are using. I try to help them along, that's an easy thing to hedge on to "I'm using this or that technology”. Well, you won't be, not for long anyway. And so, forget about this specific technology and really help them understand how to evaluate technology (this app, this software, etc.) in terms of the affordances as Melinda said. Some people hate that word, but I really like that word 'affordances'. And in this way they can evaluate any new technology. And this is kind of a toolbox that you are providing them with. How best to go about evaluating anything that comes up the pike. Then the other side of that coin is that you have to be confident in your view, your theoretical perspective on instructed second language acquisition. There's a nexus of those two when you are looking at the potential affordances. You are always coming from somewhere, theoretically. And I encourage them to really think about the perspective they have on instructed SLA, because that's the only way they can really evaluate these affordances. And I encourage them to keep in mind the importance of learner context, learner individual differences and the contexts that the learners

14. Second Language Acquisition 
are in, and that they come from. For example, you can't just talk about how mobile technology is accessible and, you know it's synchronous and image-enhanced, etc. Well if you go back and look at the TESOL technology standards (Healy et al., 2008), and you look at the work that Greg Kessler and Volker Hegelheimer and many others, they set up a grid of these different contexts: you've got high accessibility or you've got low accessibility, you've got high resource or you've got low resource. And all of these things we are talking about in terms of CALL, or TELL, it has to fit in there. They did a really good job in showing how you can harness technology for all of these different situations or how we can look at employing technology in all the situations. Like ASU, I think it's a, sometimes it seems like we are a high resource, low accessibility, and other times it's like high accessibility but absolutely low resource for what we want to do. And then you look at places in Arizona like on the Navajo reservation, where language maintenance is a huge issue, you know indigenous languages all over the world are dying out. How can you save them? And I don't know if technology can save Navajo, but it certainly won’t hurt. But the problem is, as my indigenous students tell me, there's just no connectivity on most of the Navajo reservation, and so cell phones might not help you at all. What you would have to do essentially is having a satellite hotspot, right, that five or six students could get onto and work that way. So one thing I want my future researchers to be able to do is to really look at the technology for what affordances it has, how that dovetails with your view of SLA, and then how all of that may work within the context, or the various contexts in which you are trying to operate.

Melinda: I would like to just add something. I think there is one aspect that telecollaboration and virtual exchange is bringing out that maybe hasn't been discussed much, because it's considered old fashioned. I think that all of this brings out the need to revisit and interrogate intercultural, what it means and what is interculturality. It's a term a lot of people don't even want to use anymore, they prefer 'global citizenship' or 'global cosmopolitanism' and I don't know what other terms I've been hearing lately. I think that that whole aspect needs to be interrogated again, because there is a tendency to fall with telecollaboration, especially in primary school, on sort of folkloric traits and folkloric aspects. With interconnectivity that we have nowadays, if you consider for example it was Appadurai (1996) who talked about the technoscapes and the transcultural flows, back in 1996 this was coming out. I think that we need to go back and revisit all that as well. We tend to sort encapsulate intercultural and say that if you can talk with someone from a different culture and a different language, then you are intercultural. That's not necessarily the case. So I think that is one aspect that needs to be brought back up again.

Marco: Yes, for sure. And thank you very much for mentioning that at the end, because the first question I wanted to ask you both after you talked about the definitions, nobody mentioned intercultural so I wanted to ask you about that. And I have lots of other questions, I could go for all the night, but I think we will have to wrap up. Thank you very much for your time. 


\section{References}

Appadurai, A. (1996). Modernity at large. Cultural dimensions of globalization. University of Minnesota Press.

Belz, J. A. (2003). Linguistic perspectives on the development of intercultural competence in telecollaboration. Language Learning \& Technology, 7(2), 68-117.

Colpaert, J. (2012). The "Publish and Perish" syndrome. Computer Assisted Language Learning, 25(5), 383-391.

Dooly, M., \& O’Dowd, R. (Eds). (2018). In this together: teachers' experiences with transnational, telecollaborative language learning projects. Peter Lang.

García, O., \& Otheguy, R. (2020). Plurilingualism and translanguaging: commonalities and divergences. International Journal of Bilingual Education and Bilingualism, 23(1), 1-19. https://doi.org/10.1080/13670050.2019.1598932

Goodfellow, R., \& Lamy, M.-N. (Eds). (2009). Learning cultures in online education. Continuum Books.

Healy, D., Hegelheimer, V., Hubbard, P., Ioannou-Georgiou, S., Kessler, G., \& Ware, P. (2008). TESOL technology standards framework. TESOL.

Hubbard, P. (2006). Evaluating CALL software. In L. Ducate \& N. Arnold (Eds), Calling on CALL: from theory and research to new directions in foreign language teaching (pp. 313-338). Calico.

Kern, R., \& Develotte, C. (Eds). (2018). Screens and scenes: multimodal communication in online intercultural encounters. Routledge.

Michel, M., \& Smith, B. (2018). Measuring lexical alignment during L2 chat interaction: an eye-tracking study. In S. Gass, P. Spinner \& J. Behney (Eds), Salience in second language acquisition (pp. 244-267). Routledge.

O’Dowd, R. (2005). Negotiating sociocultural and institutional contexts: the case of Spanish-American telecollaboration. Language and Intercultural Communication, 5(1), 40-56.

The EVALUATE Group. (2019). Evaluating the impact of virtual exchange on initial teacher education: a European policy experiment. Research-publishing.net. https://doi.org/10.14705/rpnet.2019.29.9782490057337

Torres, D., \& Smith, B. (2018). Computer-mediated intercultural exchanges. The TESOL Encyclopedia of English Language Teaching. https://doi.org/10.1002/9781118784235.eelt0291 


\section{Virtual Exchange?}

Published by University of Groningen Press | UGP, a not-for-profit press

Groningen, The Netherlands | UGP@rug.nl

(C) 2020 UNICollaboration (collective work)

(C) 2020 by Authors (individual work)

Journal of Virtual Exchange 2020

Edited by Carolin Fuchs, Cecilia Kennedy, and Müge Satar

Special issue edited by Marco Cappelini, Müge Satar, and Christelle Combe

Publication date: 2020/04/16

Journal of Virtual Exchange (JVE) is an online, open-access, peer-reviewed journal aimed at practitioners and researchers in the field known variously as virtual exchange, telecollaboration, or online intercultural exchange. It is the official journal of UNICollaboration (https://www.UNICollaboration.org/), the international academic organisation dedicated to supporting and promoting telecollaboration and virtual exchange in higher-level education.

Rights. The whole volume is published under the Attribution-NonCommercial-NoDerivatives 4.0 International licence (CC BY-NCND 4.0); individual articles may have a different licence. Under the CC BY-NC-ND licence, the volume is freely available online for anybody to read, download, copy, and redistribute provided that the author(s), editorial team, and publisher are properly cited. Commercial use and derivative works are, however, not permitted.

Disclaimer. University of Groningen Press does not take any responsibility for the content of the pages written by the authors of this article. The authors have recognised that the work described was not published before, or that it was not under consideration for publication elsewhere. While the information in this article is believed to be true and accurate on the date of its going to press, neither UniCollaboration nor University of Groningen Press can accept any legal responsibility for any errors or omissions. Additionally, the publisher makes no warranty, expressed or implied, with respect to the material contained herein. While University of Groningen Press is committed to publishing works of integrity, the words are the authors' alone.

Trademark notice. Product or corporate names may be trademarks or registered trademarks, and are used only for identification and explanation without intent to infringe.

Copyrighted material. Every effort has been made by the editorial team to trace copyright holders and to obtain their permission for the use of copyrighted material in this article. In the event of errors or omissions, please notify the publisher of any corrections that will need to by incorporated in future editions of this article.

Typeset by Research-publishing.net (https://research-publishing.net)

Noto fonts are open source. All Noto fonts are published under the SIL Open Font License, Version 1.1. Noto is a trademark of Google Inc. (https://www.google.com/get/noto/).

ISSN: 2647-4832 (online only)

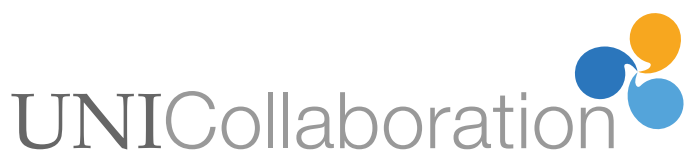

